\title{
BMJ Open Evaluations of training and education interventions for improved infectious disease management in low-income and middle-income countries: a systematic literature review
}

\author{
Pim Wilhelmus Maria van Dorst (1) , ${ }^{1}$ Simon van der Pol, ${ }^{1}$ Olawale Salami, ${ }^{2}$ \\ Sabine Dittrich (D) , ${ }^{3,4}$ Piero Olliaro, ${ }^{2}$ Maarten Postma, ${ }^{1}$ Cornelis Boersma, ${ }^{1,5}$ \\ Antoinette Dorothea Isabelle van Asselt ${ }^{1,6}$
}

To cite: van Dorst PWM, van der Pol S, Salami 0, et al. Evaluations of training and education interventions for improved infectious disease management in lowincome and middle-income countries: a systematic literature review. BMJ Open 2022;12:e053832. doi:10.1136/ bmjopen-2021-053832

- Prepublication history and additional supplemental material for this paper are available online. To view these files, please visit the journal online (http://dx.doi.org/10.1136/ bmjopen-2021-053832)

Received 26 May 2021 Accepted 25 January 2022

Check for updates

(C) Author(s) (or their employer(s)) 2022. Re-use permitted under CC BY-NC. No commercial re-use. See rights and permissions. Published by BMJ.

For numbered affiliations see end of article.

Correspondence to Dr Pim Wilhelmus Maria van Dorst; w.m.van.dorst@umcg.nl

\section{ABSTRACT}

Objectives To identify most vital input and outcome parameters required for evaluations of training and education interventions aimed at addressing infectious diseases in low-income and middle-income countries. Design Systematic review.

Data sources PubMed/Medline, Web of Science and Scopus were searched for eligible studies between January 2000 and November 2021.

Study selection Health economic and health-outcome studies on infectious diseases covering an education or training intervention in low-income and middle-income countries were included.

Results A total of 59 eligible studies covering training or education interventions for infectious diseases were found; infectious diseases were categorised as acute febrile infections (AFI), non-AFI and other non-acute infections. With regard to input parameters, the costs (direct and indirect) were most often reported. As outcome parameters, five categories were most often reported including final health outcomes, intermediate health outcomes, cost outcomes, prescription outcomes and health economic outcomes. Studies showed a wide range of per category variables included and a general lack of uniformity across studies.

Conclusions Further standardisation is needed on the relevant input and outcome parameters in this field. A more standardised approach would improve generalisability and comparability of results and allow policy-makers to make better informed decisions on the most effective and cost-effective interventions.

\section{INTRODUCTION}

Infectious diseases continue to be a major health challenge worldwide, with the highest burden in low-income and middle-income countries (LMICs). ${ }^{1}$ Over the past decades, improvements have been made in the management of infectious diseases by, among others, the introduction of widespread vaccine programmes, ${ }^{2}$ health programmes on
Strengths and limitations of this study

- This is the first review (to our knowledge) to systematically assess health economic and health-outcome literature of training or education interventions on input and outcome parameters used for improved management of infectious diseases.

- This review covers a wide variety of infectious diseases, allowing for comparisons across disease areas but also introducing high heterogeneity of results.

- This study is prone to publication bias as it includes only data from published literature.

malaria, ${ }^{3}$ HIV prevention ${ }^{4}$ and the widespread use of antimicrobials for bacterial infections. ${ }^{5}$ As a downside, widespread overuse of antimicrobials (among others) for treatment of infectious diseases has resulted in an increase of antimicrobial resistance (AMR) which could make future infections difficult or impossible to treat. Thus, to further reduce the global burden of infectious diseases, there is a need for (new) effective strategies that can be implemented at high speed with high coverage levels. ${ }^{6}$ These strategies should enable effective management of infectious diseases but also limit inappropriate use of antimicrobials to prevent further increase of AMR.

A variety of programmes have been implemented to address the management of specific diseases such as HIV, malaria or tuberculosis (TB $)^{7}$ or the prescription of antimicrobials. ${ }^{8}$ Across the different disease programmes, commonalities can be found on two major topics. First, the implementation of diagnostics is an often used strategy across programmes, such as rapid diagnostic tests (RDTs) for 
malaria diagnosis ${ }^{9}$ or home-based testing for HIV detection. ${ }^{10}{ }^{11}$ Second, education or training interventions are used across different infectious disease programmes. For example, physicians are trained and educated on improved prescription of antimicrobials, ${ }^{8}$ patients are taught about the importance of treatment adherence for antiretroviral therapy $(\mathrm{ART})^{12}$ and individuals are informed on preventive measures that can be taken to prevent HIV or malaria infections. ${ }^{13}$ Evidently, there are similarities in the approaches that are used by the different programmes, but within a programme the interventions are often focused on one specific disease (eg, malaria, HIV). Hence, with finite financial resources, a decision needs to be made by policymakers on a limited number of disease-specific programmes that can be incorporated in national health policy.

Policy-makers are informed by health economic analyses to maximise the impact on health and equity. The health economic impact is often expressed in costs per quality-adjusted life year gained (cost per QALY) or cost per disability-adjusted life year averted (cost per DALY), both of which combine morbidity and mortality (ie, quality and length of life). ${ }^{14}$ QALYs are predominantly used in higher income countries and DALYs in global health studies. ${ }^{15}$ Expressing health economic impact in cost per QALY or cost per DALY allows for comparing different health interventions across diseases. ${ }^{16}$

There are no consistent guidelines with input parameters and outcomes to report on in health economic evaluations of infectious disease interventions in LMICs. ${ }^{1718}$ To close this gap, previous endeavours have been undertaken by the VALUE-Dx consortium to review health economic assessments of diagnostic interventions for infectious diseases. ${ }^{19}$ One of the conclusions of this consortium was that there is a lack of universal outcomes in the assessment of diagnostics. Parameter categories that were found across a multitude of studies included final health outcomes (QALY, DALY), antibiotic consumption and diagnostic test performance. This provides valuable insight in parameters to use for the health economic assessment of diagnostics. However, to our knowledge, comparable research is lacking on educational or training interventions for improved management of infectious diseases.

It is important to get a better understanding of input parameters and outcomes that have been used previously to guide future research efforts, to improve the quality of health economic assessments as well as the generalisability of results. Such guidance would specifically be relevant for LMICs, where the need for improved management of infectious diseases is most urgent,${ }^{20}{ }^{21}$ where health economic frameworks are less formalised, and where limitations are encountered in applying results from health economic studies into policy-making. ${ }^{22}$ Therefore, the objective of this review is to close the knowledge gap by identifying input parameters and outcomes reported in health economic and health-outcome studies on training or education interventions for infectious diseases in LMICs.

\section{METHODS}

\section{Search strategy}

The Preferred Reporting Items for Systematic Reviews and Meta-Analyses guidelines ${ }^{23}$ were used for this study (online supplemental appendix A). A systematic search of databases was performed, including PubMed/Medline, Web of Science and Scopus. The detailed search strategy per database can be found in online supplemental appendix B. Five queries were combined in the main query, which aimed to include studies that matched the following elements:

- Population: individuals in LMICs (ie, countries and territories that are eligible to receive official development assistance as per the Organisation for Economic Co-operation and Development). ${ }^{24}$

- Intervention: programmes that include an education or training intervention.

- Disease focus: infectious diseases.

- Type of research: health economic and healthoutcomes articles.

- Time period: January 2000-November 2021.

Duplicate articles were removed after which the title and abstract were scanned independently by two researchers (PWMvD and ADIvA). Full-text analysis was performed on potentially relevant articles.

\section{Study selection}

We included studies which, based on full text analysis, met the following inclusion criteria: (1) assessing the impact of either a training or education intervention; (2) focused on infectious diseases; (3) in LMICs; (4) in humans; and (5) reporting the impact of the intervention in either health or health economic outcomes. Studies were excluded if no intervention was applied (eg, review, protocol, cross-sectional or descriptive study), if the intervention did not include a training or educational aspect, in case the training was merely focused on the introduction of RDTs as test-and-treat strategy (which was the scope of the Value Dx consortium), and if the full text was not available or not available in English.

\section{Data extraction}

Included studies were systematically analysed and documented using a digital form (Google Forms; see online supplemental appendix $\mathrm{C}$ ). Within the digital form, a distinction was made between health economic articles and health-outcomes articles. For health economic articles, a total of 57 variables were listed for data extraction, using the Consolidated Health Economic Evaluation Reporting Standards (CHEERS) checklist as a basis. ${ }^{25} \mathrm{~A}$ total of 23 variables were listed for health-outcome articles. Variables captured were related to study design, disease focus, interventions, input parameters and outcomes.

\section{Categorisation of results}

To structure the findings of the review, a categorisation of the infectious diseases was made between acute febrile infections (AFI) (fever for $<7$ days), non-AFI (fever for $>7$ 
days ${ }^{26}$ and other infectious diseases that are not primarily febrile. This categorisation is used throughout the results section, which consists of the following three subsections: interventions identified, input parameters identified and outcomes identified. Further breakdown of the results in each subsection is explained below.

For the training and education interventions that were found in the review, further clarity was given by positioning the different interventions on the healthcare spectrum, for which the definition from O'Connell et $a l^{27}$ was used. The interventions were positioned in four distinct phases, including (1) promotion of health, (2) prevention of developing a disease, (3) treatment, including patient identification and start of the treatment and (4) maintenance/postintervention care, which includes patient compliance in long-term care and provision of after care. ${ }^{27}$

Input parameters found were categorised into four categories. The first category was costs which entailed all cost parameters that were used to calculate a final cost outcome (eg, cost of medication, cost of personnel). The second category was defined as aetiology-specific characteristics, covering disease-specific parameters that could impact other parameters (eg, average duration of a disease to calculate QALYs or DALYs). The third category was population background, defined as population-related parameters that could impact other input or outcome parameters (eg, per cent of population at risk in a country). The fourth and final category consisted of intervention details, which put the intervention in a broader perspective (eg, percentage of individuals at risk targeted by the intervention).

Outcome parameters were also categorised, in nine separate categories. The first two categories were related to health effects, in which the distinction between final and intermediate outcomes was made. Final health outcomes were defined as a quantification of the health effect of an intervention, reported in a final outcome for a health (status) change (eg, death, QALYs, DALYs). Intermediate health outcomes were quantified as a change in a clinical indicator that might or might not lead to final health outcomes. ${ }^{28}$ The third category was defined as cost outcomes, which included parameters that reported the cost outcomes of a whole programme or a single intervention. The fourth category was defined as prescription outcomes, which included parameters that quantify the prescription practices like doses and frequency, often described in standardised units like the defined daily doses (DDD). The fifth category, health economic outcomes, entailed outcomes that were reported as incremental cost per unit of outcome, indicating the cost-effectiveness of an intervention (ie, cost per QALY). The sixth category was defined as behavioural outcomes, indicating the effect of an intervention on the behaviour of the targeted individual. The seventh category consisted of time-related outcomes, which included outcomes that indicated important timerelated aspects as a result of the intervention. Category eight was defined as macro-level outcomes, compromising

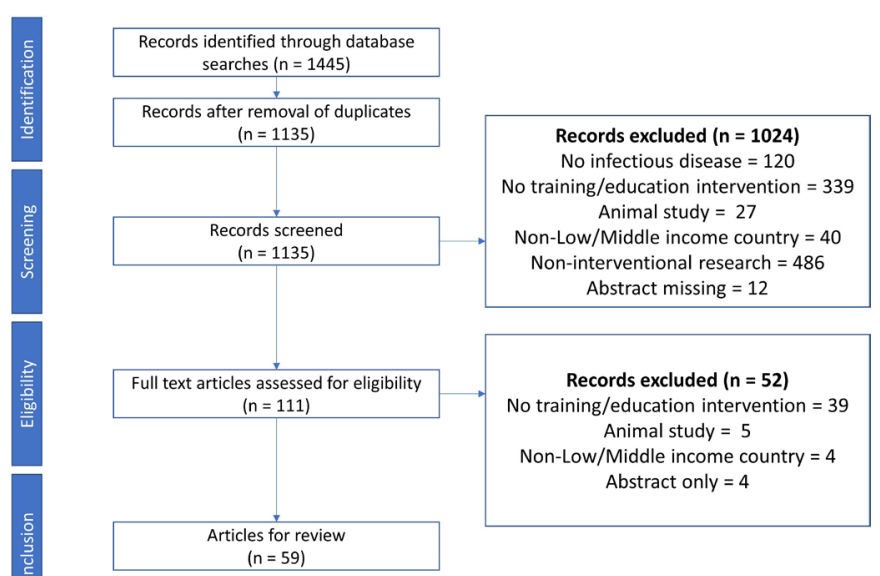

Figure 1 Preferred Reporting Items for Systematic Reviews and Meta-Analyses flow diagram.

outcomes that expressed the impact of a programme at hospital or population level. The final category was classified as miscellaneous, covering outcomes that could not be placed in one of the other categories, but which were of importance for the patient or broader society. ${ }^{28}$

\section{Patient and public involvement}

As this paper is a review comprising an assessment of the academic literature, there was no direct patient and public engagement on the paper.

\section{RESULTS}

\section{Search results}

The search strategy resulted in 1445 references, of which 310 were duplicates. Removing duplicates resulted in 1135 studies that were scanned on title and abstract. Fulltext analysis was done on 111 articles and 59 were considered to meet the study inclusion criteria (see figure 1).

\section{Baseline characteristics}

Out of the 59 included studies, the majority was performed in Africa (46\%) and Asia (34\%). Also, the majority of the articles was published between 2012 and 2020 (64\%). Out of the 59 studies, 20 studies were cost-effectiveness studies. For a complete overview, see table 1.

\section{Interventions identified}

Across the 59 studies that met the inclusion criteria, 36 unique interventions were identified (table 2). The list of interventions includes non-training and non-educational interventions that were combined with a training or educational intervention.

The studies in the current review described interventions targeting three different groups, including patients, physicians and non-physician professionals. The group of non-physician professionals consisted of retail shopkeepers, pharmacists and lay health workers. Most interventions were targeting patients $(21 / 36 ; 58 \%)$, followed by interventions targeting physicians $(13 / 36 ; 36 \%)$ and a minority targeting non-physician professionals $(8 / 36$; 
Table 1 General characteristics of studies included $(n=59)$

\begin{tabular}{lcc}
\hline Characteristics & Number & $\begin{array}{c}\text { Percentage } \\
\text { of total (\%) }\end{array}$ \\
\hline Year & & \\
\hline $2000-2002$ & 3 & 5 \\
\hline $2003-2005$ & 2 & 3 \\
\hline $2006-2008$ & 6 & 10 \\
\hline $2009-2011$ & 7 & 12 \\
\hline $2012-2014$ & 9 & 15 \\
\hline $2015-2017$ & 11 & 19 \\
\hline $2018-2020$ & 18 & 31 \\
\hline 2021 & 3 & 5 \\
\hline
\end{tabular}

Geography

\begin{tabular}{|rrr}
\hline Africa & 27 & 46 \\
\hline Asia & 20 & 34 \\
\hline Latin-America & 8 & 13 \\
\hline Europe & 3 & 5 \\
\hline Middle East & 1 & 2 \\
\hline
\end{tabular}

Study design

\begin{tabular}{lll} 
Cost-effectiveness & 20 & 34 \\
Quasi experimental cohort study & 17 & 29 \\
\hline Randomised control trial & 11 & 19 \\
$\begin{array}{l}\text { Quasi experimental retrospective } \\
\text { cohort study }\end{array}$ & 8 & 13
\end{tabular}

\begin{tabular}{|c|c|c|}
\hline $\begin{array}{l}\text { Retrospective case-control } \\
\text { study }\end{array}$ & 1 & 2 \\
\hline Non-randomised controlled trial & 2 & 3 \\
\hline \multicolumn{3}{|l|}{ Classification of infectious diseases } \\
\hline Acute febrile infections & 30 & 51 \\
\hline Inpatient infections (ASPs) & 17 & \\
\hline Malaria & 6 & \\
\hline Respiratory tract infection & 2 & \\
\hline $\begin{array}{l}\text { Upper respiratory tract } \\
\text { infection }\end{array}$ & 2 & \\
\hline $\begin{array}{l}\text { Group of acute infectious } \\
\text { diseases (caused by parasitic } \\
\text { infections, bacterial infections, } \\
\text { viral infections) }\end{array}$ & 2 & \\
\hline $\begin{array}{l}\text { Postdischarge infectious } \\
\text { disease }\end{array}$ & 1 & \\
\hline Non-acute febrile infections & 22 & 37 \\
\hline HIV & 17 & \\
\hline Tuberculosis & 4 & \\
\hline HIV and tuberculosis & 1 & \\
\hline Other non-acute infections & 7 & 12 \\
\hline Lymphatic filariasis & 1 & \\
\hline Schistosoma haematobium & 1 & \\
\hline Schistosoma japonicum & 1 & \\
\hline Leprosy & 1 & \\
\hline
\end{tabular}

Continued
Table 1 Continued

Characteristics

Number

Percentage

STD

1

Candidiasis 1

Soil-transmitted helminthiases 1

and Clonorchiasis

ASP, antimicrobial stewardship programme; STD, sexually transmitted disease.

$22 \%$ ). Some interventions were targeted at more than one group.

Among the interventions that targeted patients or caregivers, the most prevalent interventions were focused on the education of patients or caregivers by peers, community workers or health advisors. The educational goals and topics differed across the studies. Studies on HIV covered sexual and reproductive health education for adolescents and youth, ${ }^{29-32}$ and education aiming to change sexual behaviour for individuals at high risk (ie, sexually active individuals, sex workers) ${ }^{2933-37}$ Also, studies on HIV incorporated educational interventions to prevent pregnancyrelated HIV transmission ${ }^{38-40}$ and more general health education for (pregnant) women on the prevention of HIV infections. ${ }^{41}{ }^{42}$ Educational interventions in studies not targeting HIV were focused on improving knowledge of the disease (ie, infections with TB, lymphatic filariasis, leprosy, malaria, soil-transmitted helminthiasis (STH)) and promoted preventive behaviour for specific groups (ie, youth, adolescents, patients, pregnant women) or across the general population. ${ }^{30} 4143-49$

Interventions targeting the physician were mainly focused on the promotion of adequate use of antimicrobial drug therapy by physicians. ${ }^{50-68}$ In addition, physiciantargeted interventions aimed to improve adequate use of antifungal therapy ${ }^{69}$ and improved management of infectious diseases. ${ }^{70-73}$

Four studies described interventions that targeted drug retail locations (eg, pharmacies, shopkeepers) that play a vital role in appropriate drug use. By improving the health skillset of people at pharmacies and drug retailers, appropriate use of antimalarials and improved syndromic management of sexually transmitted diseases (STD) was promoted. ${ }^{74-77}$ One study described an intervention that aimed to improve the knowledge and skills of lay health workers to improve TB care provided to patients and subsequently improve treatment adherence. ${ }^{78}$

\section{Input parameters identified}

A total of 42 unique input parameters were found. Categorisation of the input variables resulted in four overarching parameter types: (1) cost parameters, (2) disease-specific parameters, (3) population background characteristics and (4) intervention details (see table 3). 


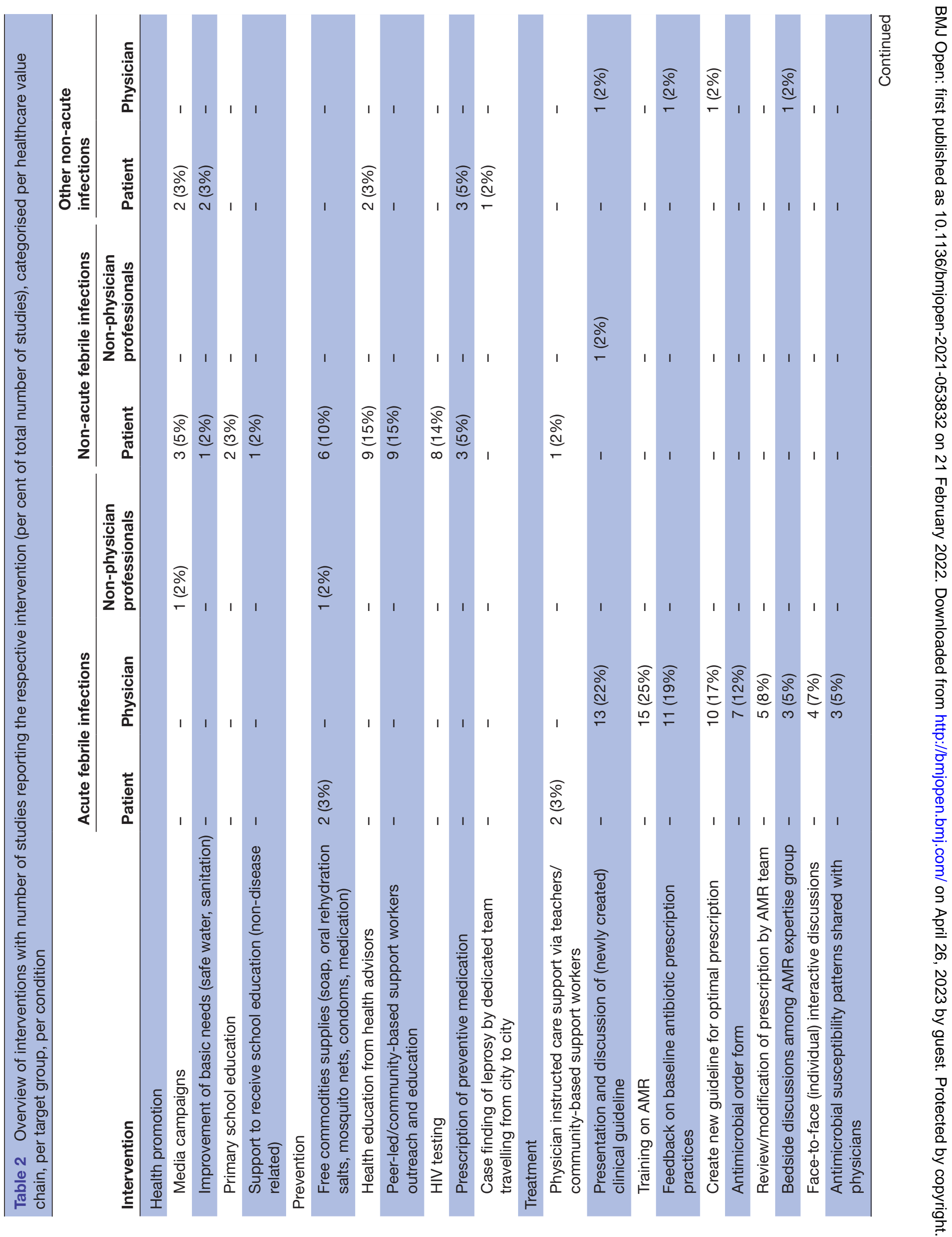




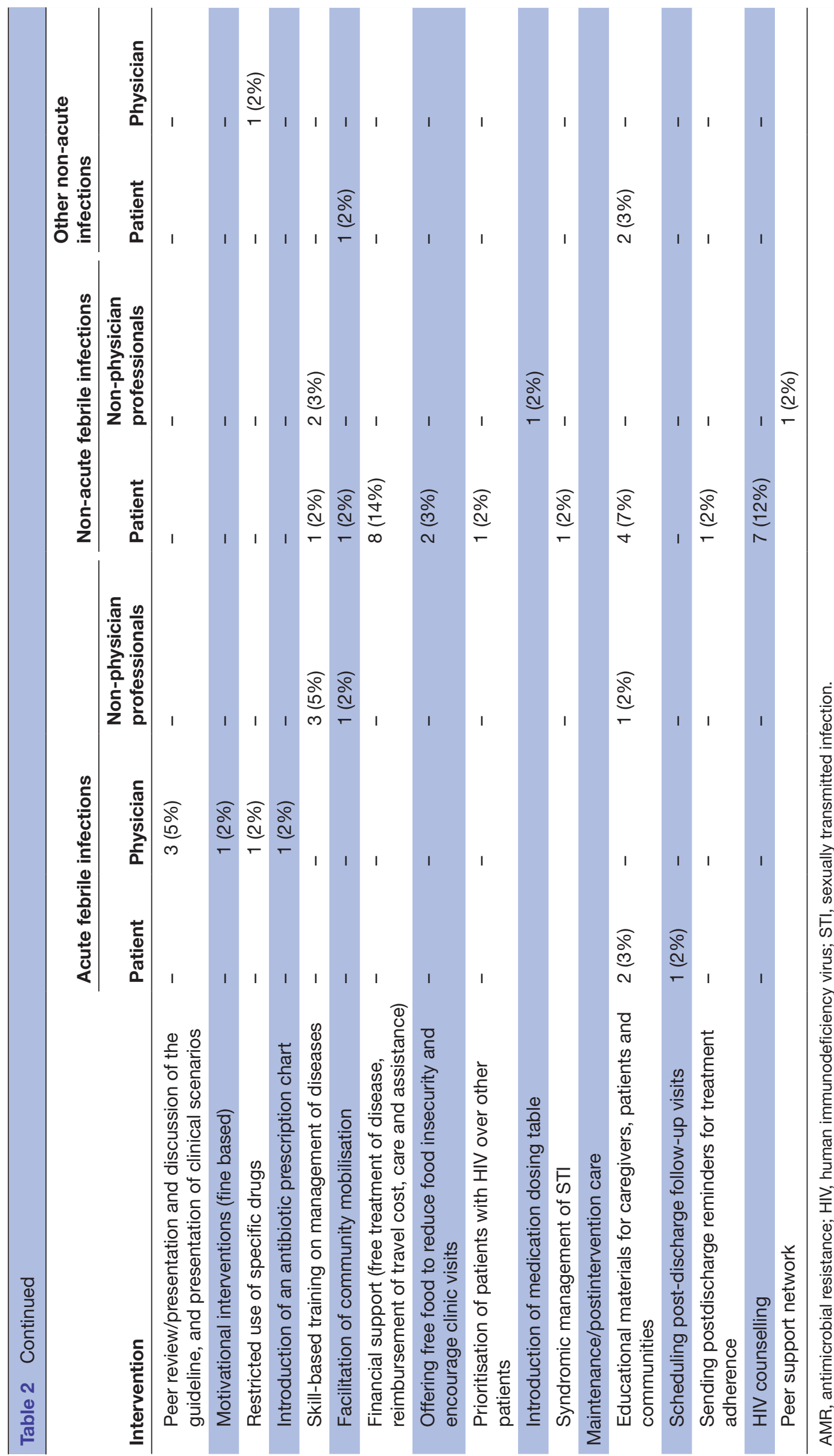


Table 3 Overview of input parameters

\begin{tabular}{|c|c|c|c|c|c|}
\hline Category & Definition & Input variables & infection & infections & infections \\
\hline Cost & $\begin{array}{l}\text { Costs related to } \\
\text { the intervention/ } \\
\text { the programme }\end{array}$ & $\begin{array}{l}\text { Programme cost: } \\
\text { Cost of travel and accommodation } \\
\text { for personnel; cost of buildings; cost } \\
\text { of overhead; cost of refreshments; } \\
\text { start-up costs; cost of training or } \\
\text { education; programme management } \\
\text { costs; programme development cost; } \\
\text { programme implementation cost; recurring } \\
\text { costs for training; personnel cost; cost } \\
\text { of transportation of supplies; cost of } \\
\text { equipment; cost for data capture and use; } \\
\text { Cost of care: } \\
\text { Routine care costs; daily cost of } \\
\text { ICU admission; average cost of one } \\
\text { inpatient day; cost of social mobilisation; } \\
\text { pharmacists costs; cost of consultation; } \\
\text { cost of lifetime treatment; cost of diagnostic } \\
\text { tests; cost of death; cost of supplies/ } \\
\text { medication; } \\
\text { Cost for the patient/caregiver: } \\
\text { Travel cost; cost of time lost for caregiver; } \\
\text { out-of-pocket costs }\end{array}$ & $\begin{array}{l}20(34 \% ; \\
67 \%)\end{array}$ & $\begin{array}{l}14(24 \% ; \\
64 \%)\end{array}$ & 5 (8\%; 71\%) \\
\hline $\begin{array}{l}\text { Aetiology- } \\
\text { specific } \\
\text { characteristics }\end{array}$ & $\begin{array}{l}\text { Disease-related } \\
\text { characteristics } \\
\text { that have impact } \\
\text { on the intervention } \\
\text { outcomes }\end{array}$ & $\begin{array}{l}\text { ART initiation age; awareness of HIV } \\
\text { status; bacterial resistance rates; disease } \\
\text { transmission rates; average duration of the } \\
\text { disease; disease prevalence }\end{array}$ & $\begin{array}{l}6(10 \% \\
20 \%)\end{array}$ & 7 (12\%; 32\%) & $4(7 \% ; 57 \%)$ \\
\hline $\begin{array}{l}\text { Population } \\
\text { background }\end{array}$ & $\begin{array}{l}\text { Background } \\
\text { information on } \\
\text { the targeted } \\
\text { population which } \\
\text { could affect the } \\
\text { outcomes of the } \\
\text { intervention }\end{array}$ & $\begin{array}{l}\text { Number of people at risk in the area; } \\
\text { average life expectancy; average number of } \\
\text { sex clients per month; average time span } \\
\text { men buy sex; average time span women } \\
\text { sell sex; proportion of individuals using } \\
\text { condoms }\end{array}$ & - & $4(7 \% ; 18 \%)$ & 1 (2\%; 14\%) \\
\hline
\end{tabular}

ART, antiretroviral therapy; HIV, human immunodeficiency virus; ICU, Intensive Care Unit.

The majority of the input parameters detailed the costs of an intervention (27 unique parameters). Within the cost category, a clear distinction was present between cost related to the programme, cost for care and cost for the patient and caregiver. Great variety existed among the studies, none of the cost parameters was used across all studies.

\section{Acute febrile infections}

No consistent approach was found among studies that included cost input parameters. A large proportion of

Reported in N studies (\% of total; \% of total within the respective category)

\begin{tabular}{|c|c|c|c|c|c|}
\hline Category & Definition & Input variables & $\begin{array}{l}\text { Acute } \\
\text { febrile } \\
\text { infection }\end{array}$ & $\begin{array}{l}\text { Non-acute } \\
\text { febrile } \\
\text { infections }\end{array}$ & $\begin{array}{l}\text { Other } \\
\text { non-acute } \\
\text { infections }\end{array}$ \\
\hline Cost & $\begin{array}{l}\text { Costs related to } \\
\text { the intervention/ } \\
\text { the programme }\end{array}$ & $\begin{array}{l}\text { Programme cost: } \\
\text { Cost of travel and accommodation } \\
\text { for personnel; cost of buildings; cost } \\
\text { of overhead; cost of refreshments; } \\
\text { start-up costs; cost of training or } \\
\text { education; programme management } \\
\text { costs; programme development cost; } \\
\text { programme implementation cost; recurring } \\
\text { costs for training; personnel cost; cost } \\
\text { of transportation of supplies; cost of } \\
\text { equipment; cost for data capture and use; } \\
\text { Cost of care: } \\
\text { Routine care costs; daily cost of } \\
\text { ICU admission; average cost of one } \\
\text { inpatient day; cost of social mobilisation; } \\
\text { pharmacists costs; cost of consultation; } \\
\text { cost of lifetime treatment; cost of diagnostic } \\
\text { tests; cost of death; cost of supplies/ } \\
\text { medication; } \\
\text { Cost for the patient/caregiver: } \\
\text { Travel cost; cost of time lost for caregiver; } \\
\text { out-of-pocket costs }\end{array}$ & $\begin{array}{l}20(34 \% ; \\
67 \%)\end{array}$ & $\begin{array}{l}14(24 \% \\
64 \%)\end{array}$ & $5(8 \% ; 71 \%)$ \\
\hline $\begin{array}{l}\text { Aetiology- } \\
\text { specific } \\
\text { characteristics }\end{array}$ & $\begin{array}{l}\text { Disease-related } \\
\text { characteristics } \\
\text { that have impact } \\
\text { on the intervention } \\
\text { outcomes }\end{array}$ & $\begin{array}{l}\text { ART initiation age; awareness of HIV } \\
\text { status; bacterial resistance rates; disease } \\
\text { transmission rates; average duration of the } \\
\text { disease; disease prevalence }\end{array}$ & $\begin{array}{l}6(10 \% \\
20 \%)\end{array}$ & 7 (12\%; 32\%) & $4(7 \% ; 57 \%)$ \\
\hline $\begin{array}{l}\text { Intervention } \\
\text { details }\end{array}$ & $\begin{array}{l}\text { Details of the } \\
\text { intervention } \\
\text { that put the } \\
\text { intervention } \\
\text { in a broader } \\
\text { perspective }\end{array}$ & $\begin{array}{l}\text { Number of individuals reached with the } \\
\text { intervention; efficacy of the intervention; the } \\
\text { proportion of the population at risk targeted } \\
\text { by the intervention }\end{array}$ & - & 5 (8\%; 23\%) & $1(2 \% ; 14 \%)$ \\
\hline
\end{tabular}

Corst of buildings; cost start-up costs; cost of traini education; programme management osts; programme development cost costs for training; personnel cost; cost of transportation of supplies; cost of Cost of care:

Routine care costs; daily cost of ICU admission; average cost of one inpatient day; cost of social mobilisation tests; cost of death; cost of supplies/

edication

Cost for the patient/caregiver:

Travel cost; cost of time lost for caregiver; out-of-pocket costs

the studies only included the cost of medication, not taking any other programme or care-related costs into account. 5051535962646768 Though, there were also studies that took a more extensive approach by reporting both cost of care (eg, cost of medication, cost of consultation) and programme costs (eg, cost of personnel, cost of training and cost of programme management). ${ }^{55-57607275767980}$ Across all studies in the review, only three studies included the cost for the patient and caregiver. These studies were cost-effectiveness studies of 
malaria interventions performed from a societal perspective. $^{72} 7679$

\section{Non-acute febrile infections}

All non-AFI studies that reported costs as input parameters, included at least one variable on the cost of care and one variable on costs of the programme. ${ }^{29} 30333436373941424581-84$ The cost of supplies such as condoms and medication was reported most frequently. ${ }^{29} 333437394142458183$ None of the studies included the costs for the patient and caregiver.

\section{Other non-acute infections}

Studies that included costs for interventions targeting non-acute infections reported costs in different ways. One study on candidiasis only included the cost of medication, ${ }^{69}$ while studies on STD, Schistosoma japonicum, STH and leprosy incorporated both costs of care and cost of the programme. ${ }^{4347485}$ None of the studies included the costs for the patient and caregiver.

\section{Outcomes identified}

A total of 81 unique outcomes were reported in 59 studies which are categorised into 9 categories (see table 4 ). In the section below, the five categories that were reported in most studies are reviewed in more detail.

\section{Final health outcomes}

Out of the 59 studies, 21 studies reported final health outcomes. Final health outcomes-reported in DALYs averted, QALYs gained, years of life saved (YLS), mortality rate, cured rate and deaths averted-were found in studies across all three infectious disease categories.

\section{Acute febrile infections}

Among the studies on AFI, one study on malaria reported DALYs and deaths averted, calculated based on the probability of death for a child with fever for whom treatment is first sought from a shop, with and without the intervention. ${ }^{75}$ Seven studies on inpatient infections reported mortality rates (increase/decrease) as a result of the intervention. ${ }^{50545658606786}$ One study on postdischarge infections reported final health outcomes in deaths averted, defined as hospitalised patients that survive 30 days after discharge. $^{61}$

\section{Non-acute febrile infections}

In total, six studies on HIV reported DALYs averted, calculated from the number of infections averted. ${ }^{29} 3436394183$ Besides the studies reporting DALYs averted, there was one study on HIV reporting QALYs to quantify the impact of the prevention of mother-to-child HIV transmission. ${ }^{42}$ To estimate QALYs, the difference between the expected number of QALYs of a child living with and without HIV was calculated. ${ }^{42}$ One study on HIV reported outcomes in YLS calculated from the life years lost as a result of lossto-follow-up from ART. ${ }^{81}$ Two studies on TB reported the final health outcomes as the number of patients cured, defined as individuals who are smear or culture negative in the last month of treatment, ${ }^{44} 78$ and another study on
TB reported the outcome as the reduction in mortality rate as a result of the intervention. ${ }^{45}$

\section{Other non-acute infections}

Only one study in the category of other non-acute infections reported a final health outcome. The study on leprosy reported the number of patients cured, defined as individuals completing the therapy. ${ }^{43}$

\section{Intermediate health outcomes}

Acute febrile infections

Among the studies reporting on AFI, the most frequently reported intermediate health outcome was the number of patients that are correctly treated, covered in studies on inpatient infections, malaria and acute respiratory tract infections. $50515556636671-73767677$ The recurrence rate, also indicated as unexpected readmission rates, was reported in six studies covering inpatient infections, respiratory tract infection and postdischarge infections. 545658606786 Other intermediate health-outcomes reported in studies on AFI were less widely reported. These outcomes included the number of cases diagnosed with malaria, ${ }^{72}$ and the number of adverse events occurred after implementation of antimicrobial stewardship programmes (ASPs) for improved management of inpatient infections. $^{63} 64$

\section{Non-acute febrile infections}

The two most reported intermediate health outcomes in studies on HIV or TB were the number of cases diagnosed $^{8487}$ and the number of infections averted. ${ }^{29} 3442$ Across all studies in the review, only one study reported the quality of life of the patient, which was measured using the EQ-5D with patients with TB. ${ }^{44}$ Disease-specific clinical outcomes were also found in studies on HIV and TB. Examples of disease-specific outcomes were reduced TB stigma or CD4 count slope. ${ }^{30} 88$

\section{Other non-acute infections}

One study on STD reported intervention outcomes in the number of patients correctly treated. ${ }^{74}$ Two studies, on STD and candidiasis, reported the results in the number of unexpected readmissions. ${ }^{69} 74$ The number of cases diagnosed was reported in one study on leprosy ${ }^{43}$ and the increase/decrease of infections as a result of the intervention was reported in two studies covering S. japonicum and STH infections. ${ }^{4985}$

\section{Cost outcomes}

The cost impact of an intervention was reported in an aggregate form (ie, total programme costs and total cost saved) or on a per-unit basis (eg, per person reached). The aggregated total costs of the programme/intervention $3436394349535762656768717576798082-85$ and the costs saved as a result of the intervention $36425354565760606467-69$ were often reported across all three infectious disease categories.

Only studies on non-AFI reported the cost per unit. Three studies on HIV reported cost per person 
Reported in N studies (\% of total; \% of total within the respective category)

\begin{tabular}{|c|c|c|c|c|c|}
\hline \multirow[b]{2}{*}{ Category } & \multirow[b]{2}{*}{ Definition } & \multirow[b]{2}{*}{ Outcome variables } & \\
\hline & & & $\begin{array}{l}\text { Acute febrile } \\
\text { infections }\end{array}$ & $\begin{array}{l}\text { Non-acute } \\
\text { febrile } \\
\text { infections }\end{array}$ & $\begin{array}{l}\text { Other } \\
\text { non-acute } \\
\text { infections }\end{array}$ \\
\hline $\begin{array}{l}\text { Final health } \\
\text { outcomes }\end{array}$ & $\begin{array}{l}\text { Quantification of } \\
\text { the health effect } \\
\text { of an intervention, } \\
\text { addressing the } \\
\text { length or quality } \\
\text { of life }\end{array}$ & $\begin{array}{l}\text { QALY; DALY; YLS; deaths averted; mortality } \\
\text { rate; mortality increase/decrease; cured rate }\end{array}$ & 11 (19\%; 37\%) & $9(15 \% ; 41 \%)$ & $1(2 \% ; 14 \%)$ \\
\hline $\begin{array}{l}\text { Intermediate health } \\
\text { outcomes }\end{array}$ & $\begin{array}{l}\text { Quantification of } \\
\text { the health effects } \\
\text { of an intervention } \\
\text { as a change in } \\
\text { clinical indicator } \\
\text { that may or may } \\
\text { not lead to final } \\
\text { health outcomes }\end{array}$ & $\begin{array}{l}\text { Disease-specific outcomes; number of } \\
\text { cases correctly treated; infections averted; } \\
\text { number cases detected with disease; } \\
\text { infection rates; recurrence rates; number } \\
\text { of adverse drug reactions; \% positive } \\
\text { and negative tests; number of individuals } \\
\text { receiving treatment; quality of life }\end{array}$ & 19 (32\%; 63\%) & $8(14 \% ; 36 \%)$ & $5(8 \% ; 71 \%)$ \\
\hline $\begin{array}{l}\text { Prescription } \\
\text { outcomes }\end{array}$ & $\begin{array}{l}\text { Quantification } \\
\text { of the impact of } \\
\text { an intervention } \\
\text { on prescribing } \\
\text { practices }\end{array}$ & $\begin{array}{l}\text { Antibiotic use density; DDD/100 patients; } \\
\text { (antibiotic) prescription rate; DDD/1000 or } \\
100 \text { patient days; number of inappropriate } \\
\text { prescriptions; total antibiotic days } \\
\text { of therapy/1000 patient days; \% of } \\
\text { prescriptions containing more than one } \\
\text { antibiotic; \% of prescriptions having broad } \\
\text { spectrum antibiotics; grams of antibiotics } \\
\text { prescribed; number of times adjustment of } \\
\text { antibiotic prescription done }\end{array}$ & 19 (32\%; 63\%) & - & $1(2 \% ; 14 \%)$ \\
\hline $\begin{array}{l}\text { Behaviour } \\
\text { outcomes }\end{array}$ & $\begin{array}{l}\text { Outcomes that } \\
\text { indicate the effect } \\
\text { of the intervention } \\
\text { on health-related } \\
\text { behaviour of the } \\
\text { targeted individual }\end{array}$ & $\begin{array}{l}\text { Adherence rates; attrition rates (including } \\
\text { loss-to-follow-up and mortality); number of } \\
\text { admissions; loss-to-follow-up rate; averted } \\
\text { loss-to-follow-up; \% retention in care; } \\
\text { completion of follow-up visits; number of } \\
\text { referrals to secondary health clinics by GP; } \\
\text { number of women giving birth at health } \\
\text { facility; number of ANC visits; number } \\
\text { of cases that did postpartum check-up; } \\
\text { number performing exclusive breast feeding; } \\
\% \text { using family planning; }\end{array}$ & $6(10 \% ; 20 \%)$ & 10 (17\%; 45\%) & $1(2 \% ; 14 \%)$ \\
\hline $\begin{array}{l}\text { Time-related } \\
\text { outcomes }\end{array}$ & $\begin{array}{l}\text { Quantification of } \\
\text { the time-related } \\
\text { component of an } \\
\text { intervention }\end{array}$ & $\begin{array}{l}\text { Time efficiency gain; time to event; duration } \\
\text { of hospital stay; per person life-expectancy } \\
\text { losses due to loss-to-follow-up; time till } \\
\text { loss-to-follow-up }\end{array}$ & $7(12 \% ; 23 \%)$ & $4(7 \% ; 18 \%)$ & - \\
\hline
\end{tabular}




$\begin{array}{lllll} & & & \text { Reported in N studies (\% of total; \% of total } \\ \text { within the respective category) }\end{array}$

ANC, antenatal care; DALY, disability-adjusted life years; DDD, defined daily doses; GP, general practitioner; HIV, human immunodeficiency virus; ICU, intensive care unit; QALY, quality-adjusted life year; YLS, years of life saved.

reached ${ }^{29} 3336$ and one study on HIV indicated the cost per individual tested. ${ }^{33}$

\section{Health economic outcomes}

Acute febrile infections

Only six studies in the category of AFI reported health economic outcomes, out of which four were on malaria. Studies on malaria reported health economic outcomes as the cost per case adequately treated, ${ }^{72} 7576$ cost per DALY averted ${ }^{75}$ and cost per death averted. ${ }^{75}$ Cost per death averted was also reported in a study on inpatient infections. ${ }^{61}$ The cost per percentage reduction in antibiotic prescription was reported once in a study on upper respiratory tract infection. ${ }^{80}$

\section{Non-acute febrile infections}

Health economic outcomes were most often reported in studies on non-AFI. Twelve out of the 17 studies on HIV reported on the cost-effectiveness of the intervention. Variables included were cost per infection averted, ${ }^{34364287}$ cost per QALY, ${ }^{42}$ cost per HIV case detected ${ }^{8487}$ cost per DALY averted, 293436394183 cost per averted loss-to-follow-up, ${ }^{30} 82$ cost per YLS, ${ }^{81}$ cost per reduction in male sexual partners ${ }^{37}$ and cost per $\%$ increase in condom use. ${ }^{37}$

Cost-effectiveness thresholds, which indicates the maximum amount a country or organisation is willing to pay for a unit of health-outcome, were only applied in studies on HIV. The thresholds ranged between one to five times gross domestic product per capita per DALY averted $^{29} 363941$ or per YLS. ${ }^{81}$ For all five studies that applied cost-effectiveness thresholds, the cost per DALY averted or cost per YLS of the interventions fell below the cost-effectiveness thresholds. Hence, these interventions were considered cost-effective compared with the standard of care. . $^{293394181}$

\section{Other non-acute infections}

In the category of other non-acute infections, health economic outcomes were rarely reported. One study on $S$. japonica reported cost per infection averted ${ }^{85}$ and one study on STD reported the cost per case adequately treated. ${ }^{74}$

\section{Prescription outcomes}

The category of prescription outcomes included outcomes reported in studies that aimed for more appropriate use of antimicrobials and antifungals by physicians, and was predominantly found in studies on AFI and in one study on other non-AFI. The category of prescription outcomes provided insight into three main factors: (1) the overall prescription practices by physicians, (2) the quality of the prescription practices and (3) the quantitative prescription details (see table 4).

As an indicator of the overall prescription practices, three outcomes were reported: the antibiotic prescription rate (number of times antibiotics prescribed), ${ }^{55} 57626567697080$ percentage of the prescriptions containing more than one antibiotic $^{65}$ and percentage of prescriptions containing broad-spectrum antibiotics. ${ }^{65}$

The quality of the prescription practices was reflected by the number of inappropriate prescriptions, defined as incorrect antimicrobial prescribed, incorrect dose prescribed, incorrect duration prescribed or incorrect decision to prescribe antimicrobials. ${ }^{52626869}$ Another 
outcome that indicated the quality of prescription practices was the number of times adjustment of prescription was done. ${ }^{50}$

The quantitative details of the prescription were reported in a variety of ways. Four studies reported the total DDD prescribed. ${ }^{646768} 80$ The DDD is a validated method to standardise the number of doses consumed and is developed by the WHO. Nine studies reported the total DDD per 1000 patient days or 100 patients treated. ${ }^{51535456596067-69}$ One study reported the total antibiotic days of therapy per 1000 patient days, defined as the days of antibiotic therapy administered to the patients independent of the doses. The days of therapy was calculated by multiplying the number of doses received by the dosing interval (in hours) and then divided by 24 hours for each antibiotic the patient received. ${ }^{58}$ The antibiotic use density was given once, which was equal to DDD per 100 patient days, and was calculated by multiplying the DDD by 100 , divided by the number of patient. ${ }^{66}$ One study reported the antibiotic prescription in total grams ${ }^{68}$ All studies on inpatient infections that reported on antibiotic consumption reported a decrease in the total antibiotics consumed ${ }^{51} 53545658-606466-69$ with some small increases on individual antibiotics. ${ }^{50} 5153575960626467$

\section{DISCUSSION}

The results of the current review provide insight in the wide range of programmes that aim for improved infectious disease management in LMICs. The programmes consisted of one or more interventions that span across the healthcare pathway and target different stakeholder groups including patients, physicians and non-physician professionals. The input and outcome parameters reported in the studies did not show a consistent and generalisable set of metrics used across all studies. However, by grouping the individual variables into categories, it became evident that four input categories and nine outcome categories could be considered when reporting the impact of a programme targeting infectious diseases.

Heterogeneity in outcomes is a well-known factor of influence in clinical research. ${ }^{89}$ Several initiatives have started to improve the standardisation of metrics measured and reported in clinical studies. One of these initiatives is the Core Outcome Measures in Effectiveness Trials (https://www.comet-initiative.org/) initiative, which launched in 2010 to coordinate efforts in the development of core outcome sets (COSs) across a wide range of areas of health. The definition of COS is 'an agreed standardized collection of outcomes that should be measured and reported for a specific area of health' ${ }^{90}$ Unfortunately, for infectious disease, the number of COS developed is limited, existing COS on infectious diseases has not been updated recently ${ }^{91}{ }^{92}$ and the involvement of LMICs in the development of the COS was low. ${ }^{93}$ Therefore, we suggest that further research will continue with a critical assessment of the categories and metrics found in the current review. These efforts could function as valuable input to establish an initial COS for infectious disease management programmes in LMIC.

Reporting on final health outcomes is crucial to allow comparisons between interventions. Final health outcomes are standardised and widely used outcomes across multiple disease areas, as opposed to intermediate health outcomes that could be disease specific and thereby making it difficult to extrapolate and compare with other disease areas. The most used final health outcome in global health studies and in LMICs is the DALYs averted, which is used to define the burden of the disease. ${ }^{15}$ Also within the current review, DALYs averted were the most frequent reported final health outcome, mostly found in studies on non-AFI (eg, HIV) 293436394183 and only one time in a study on AFI (eg, malaria). ${ }^{75}$ Studies on AFI more often report on an increase or decrease in mortality rate. However, as opposed to DALYs, mortality rates do not quantify the impact of a disease on morbidity, ${ }^{94}$ which is why the DALY is preferred over the mortality rate. One of the potential reasons for not reporting the DALYs could be the lack of local data for estimating the DALYs, which appeared to be an important reason for researchers in LMIC to not include the DALYs averted.$^{95}$ Also, infectious diseases are often self-limiting and of short duration, thereby having a small impact on the estimated DALYs per patient, but on population level could still result in a substantial disease burden. ${ }^{1}$ To encourage researchers in reporting on important outcome parameters like DALYs averted, the Guide to Economic Analysis and Research (GEAR; http://www.gear4health.com/) online resource was introduced as a reliable aid for researchers in LMICs that provide solutions for methodological difficulties. ${ }^{22}$ Although it could be a helpful resource, none of the studies in the current review mentioned or referred to the GEAR resource. Hence, further dissemination of the GEAR resource among researchers performing healtheconomic analyses for LMICs could be of benefit to improve standardisation across studies.

The impact of a health intervention should logically be expressed in health outcomes, but also the financial impact should be considered. Being able to compare interventions on health-related and economic outcomes, allows policy-makers to create health policy with the intervention that maximises the health impact per monetary unit spent. There are different approaches researchers could take when calculating the cost of an intervention, considering direct and indirect costs. Within the current review, most of the studies reporting the costs of an intervention only included direct costs, with substantial variations in the type of direct costs included. These methodological variations have impact on the results and make comparisons between studies less reliable. A more standardised approach for calculating costs would improve generalisability of results and thereby enhance the ability to compare outcomes between different studies. Wider implementation of existing guidelines could be an important step towards more generalisable results for studies in LMICs. For example, for health economic studies, the CHEERS 
provides guidance in the reporting of health economic assessments. The CHEERS guideline includes some highlevel recommendations in the decision on what costs to include, depending on the perspective that is taken (eg, healthcare system, societal).$^{25}$ Also, for studies on ASPs, the US guideline incorporated recommendations to include costs on programme management, salary for stewardship personnel and medication purchasing costs. ${ }^{96}$ With the US guideline for studies on ASPs and the CHEERS guideline for health economic assessments, some guidance already exists and could be more broadly applied as an initial step towards more generaliable cost outcomes.

Indicating the impact of an intervention on prescription practices has been considered as an important outcome variable. As such, standardised approaches are introduced by WHO to enable clear and concise reporting of prescription outcomes. ${ }^{97}$ Especially in the case of antimicrobial prescriptions, the dose, frequency and duration are important to assess the impact of an intervention on the consumption and the related AMR. Within the current review, the DDD was the most reported outcome in the category of prescriptions outcomes. The DDD is a standardised approach but is impacted by weight-based dosing as done for paediatrics. ${ }^{96}$ Therefore, instead, days of therapy is suggested as a more valuable parameter since it is not impacted by dose adjustments. When following the guidelines from the Infectious Diseases Society of America and the Society for Healthcare Epidemiology of America, days of therapy is the preferred option.$^{96}$ In the present review, only one study reported the outcomes in days of therapy ${ }^{58}$ which could imply that the impact of weight-based dosing has been overlooked in the other studies. Moving forward, to give a more complete picture of antimicrobial prescription, researchers could consider to include the antimicrobial use expressed in days of therapy if possible.

The studies on infectious diseases that reported antimicrobial consumption in DDD or days of therapy as the main outcome measure $5153545658-60646669$ did not report final health outcomes in DALY, QALY or YLS. Thereby making it challenging to compare the effect of these interventions with interventions not reporting DDDs or days of therapy. Translating antimicrobial use into a value that indicates the burden of the disease in more generalisable outcomes, such as DALYs, is challenging and comes with great uncertainty. ${ }^{98}$ Another possibility is to convert antimicrobial use to costs per antimicrobial prescribed to account for future resistance, as is done in some studies. ${ }^{99} 100$ However, these estimates also come with high uncertainty and there is a risk that the actual costs are far higher than the best estimates. ${ }^{101}$ Therefore, future research should focus on the quantification of antimicrobial use in more generalisable outcomes to better reflect the actual value of interventions that aim for appropriate antimicrobial use as part of the infectious disease management strategy.

The current literature review is limited in the following aspects: first, the variables found in this review show a high heterogeneity resulting in low generalisability. This could be a result of the wide scope of aetiologies included, in addition to the fact that the input and outcome parameters are often context specific. However, generalisability should, to a certain extent, also apply to interventions targeting different aetiologies to allow policy-makers to decide on the most cost-effective strategy. There should at least be a set of core outcomes across aetiologies that functions as the minimum of what should be included, still allowing for additional disease-specific measures to be added. Second, the results of the current review could guide researchers in the process of defining input and outcome parameters to report on for health economic research on infectious diseases but does not offer a concrete list of input and outcome parameters. Further research is needed to come to a COS for infectious diseases along with broad implementation and knowledge dissemination of currently available guidelines.

To our knowledge, the current study is the first review that provides an overview of health economic and healthoutcome studies on training or education interventions for improved management of infectious diseases. Thereby, the current study offers valuable insights for future health economic assessments on programmes in which education is integral part of the intervention.

\section{CONCLUSION}

In conclusion, it can be said that standardisation of parameters is lacking across studies on infectious disease programmes. For input parameters, the most reported category was costs. For outcomes, studies reported most often on final health outcomes, intermediate health outcomes, cost outcomes, prescription outcomes and health economic outcomes. We recommend that further research will be performed on the definition of a COS for infectious diseases in LMICs.

\section{Author affiliations}

${ }^{1}$ University Medical Center Groningen, Department of Health Sciences, University of Groningen, Groningen, The Netherlands

${ }^{2}$ Foundation for Innovative New Diagnostics, Geneva, Switzerland ${ }^{3}$ Malaria/Fever Program, Foundation for Innovative New Diagnostics, Geneva, Switzerland

${ }^{4}$ Nuffield Department of Medicine, University of Oxford, Oxford, UK ${ }^{5}$ Department of Management Sciences, Open University, Heerlen, The Netherlands ${ }^{6}$ University Medical Center Groningen, Department of Epidemiology, University of Groningen, Groningen, The Netherlands

Contributors All authors contributed to the study conception and design. Material preparation, data collection and analysis were performed by PWMvD, ADIvA and SvdP. The first draft of the manuscript was written by PWMvD and all authors commented on previous versions of the manuscript. All authors read and approved the final manuscript. PWMvD is the guarantor of this study.

Funding This research is funded by the Foundation for Innovative new Diagnostics (FIND).

Competing interests MP received grants and honoraria from various pharmaceutical companies all unrelated to this research.

Patient consent for publication Not applicable.

Ethics approval This study does not involve human participants. 
Provenance and peer review Not commissioned; externally peer reviewed.

Data availability statement Data are available upon reasonable request. The datasets generated and/or analysed during the current study are available from the corresponding author on reasonable request.

Supplemental material This content has been supplied by the author(s). It has not been vetted by BMJ Publishing Group Limited (BMJ) and may not have been peer-reviewed. Any opinions or recommendations discussed are solely those of the author(s) and are not endorsed by BMJ. BMJ disclaims all liability and responsibility arising from any reliance placed on the content. Where the content includes any translated material, BMJ does not warrant the accuracy and reliability of the translations (including but not limited to local regulations, clinical guidelines, terminology, drug names and drug dosages), and is not responsible for any error and/or omissions arising from translation and adaptation or otherwise.

Open access This is an open access article distributed in accordance with the Creative Commons Attribution Non Commercial (CC BY-NC 4.0) license, which permits others to distribute, remix, adapt, build upon this work non-commercially, and license their derivative works on different terms, provided the original work is properly cited, appropriate credit is given, any changes made indicated, and the use is non-commercial. See: http://creativecommons.org/licenses/by-nc/4.0/.

\section{ORCID iDs}

Pim Wilhelmus Maria van Dorst http://orcid.org/0000-0001-8401-0932

Sabine Dittrich http://orcid.org/0000-0002-4522-2788

\section{REFERENCES}

1 Vos T, Lim SS, Abbafati C, et al. Global burden of 369 diseases and injuries in 204 countries and territories, 1990-2019: a systematic analysis for the global burden of disease study 2019. Lancet 2020;396:1204-22.

2 World Health Organization. Global vaccine action plan 2011-2020, 2013. Available: https://www.who.int/publications-detail-redirect/ global-vaccine-action-plan-2011-2020 [Accessed 2 Apr 2021].

3 World Health Organization. World malaria report 2020: 20 years of global progress \& challenges, 2020. Available: https://www.who.int/ publications-detail-redirect/9789240015791 [Accessed 2 Apr 2021]

4 World Health Organization. Hiv/Aids, 2020. Available: https://www. who.int/news-room/fact-sheets/detail/hiv-aids [Accessed $2 \mathrm{Apr}$ 2021].

5 Aminov RI. A brief history of the antibiotic era: lessons learned and challenges for the future. Front Microbiol 2010;1:134.

6 World Health Organization. Global health sector strategy on HIV: 2016-2021, 2016. Available: https://www.who.int/publicationsdetail-redirect/WHO-HIV-2016.05 [Accessed 2 Apr 2021].

7 World Health Organization. Accelerating progress on HIV, tuberculosis, malaria, hepatitis and neglected tropical diseases: a new agenda for 2016-2030, 2015. Available: http://apps.who.int/iris/ bitstream/10665/204419/1/9789241510134_eng.pdf [Accessed 2 Apr 2021].

8 Cox JA, Vlieghe E, Mendelson M, et al. Antibiotic stewardship in low- and middle-income countries: the same but different? Clin Microbiol Infect 2017;23:812-8.

9 Mubi M, Janson A, Warsame $M$, et al. Malaria rapid testing by community health workers is effective and safe for targeting malaria treatment: randomised cross-over trial in Tanzania. PLoS One 2011;6:e19753.

10 Dalal W, Feikin DR, Amolloh M, et al. Home-Based HIV testing and counseling in rural and urban Kenyan communities. J Acquir Immune Defic Syndr 2013;62:e47.

11 Sekandi JN, Sempeera H, List J, et al. High acceptance of homebased HIV counseling and testing in an urban community setting in Uganda. BMC Public Health 2011;11:730.

12 Musayón-Oblitas Y, Cárcamo C, Gimbel S. Counseling for improving adherence to antiretroviral treatment: a systematic review. AIDS Care 2019;31:4-13.

13 Vergidis PI, Falagas ME. Meta-Analyses on behavioral interventions to reduce the risk of transmission of HIV. Infect Dis Clin North Am 2009;23:309-14.

14 Robberstad B. QALYs vs DALYs vs Lys gained: what are the differences and what difference do they make for health care priority setting? Nor Epidemiol 2005;15.

15 Chen A, Jacobsen KH, Deshmukh AA. The evolution of the disability-adjusted life year (DALY). Socioecon Plann Sci 2015;49:10-15.
16 Murray CJL, Ezzati M, Flaxman AD, et al. GBD 2010: design, definitions, and metrics. Lancet 2012;380:2063-6.

$17 \mathrm{~J}-\mathrm{WH}$ D, Vemer P, Friedrich AW. Financial evaluations of antibiotic stewardship programs - a systematic review. Front Microbiol 2015;6.

18 Coulter S, Merollini K, Roberts JA, et al. The need for costeffectiveness analyses of antimicrobial stewardship programmes: a structured review. Int J Antimicrob Agents 2015;46:140-9.

19 der PSV, Rojas P, Juárez C. PIN132 HEALTH-ECONOMIC modelling of infectious disease diagnostics: current approaches and future opportunities. Value Health 2019;22:S660.

20 Crump JA, Kirk MD. Estimating the burden of febrile illnesses. PLoS Negl Trop Dis 2015;9:e0004040.

21 O'Neill J. Tackling drug-resistant infections globally: final report and recommendations. government of the United Kingdom, 2016 Available: https://apo.org.au/node/63983 [Accessed 3 Feb 2021].

22 Adeagbo CU, Rattanavipapong W, Guinness L, et al. The development of the guide to economic analysis and research (GEAR) online resource for low- and middle-income countries health economics practitioners: a commentary. Value Health 2018;21:569-72.

23 Moher D, Liberati A, Tetzlaff J, et al. Preferred reporting items for systematic reviews and meta-analyses: the PRISMA statement. PLoS Med 2009;6:e1000097.

24 Organisation for Economic Co-operation and Development (OECD). DAC list of ODA recipients effective for reporting on 2020 flows, 2020. Available: https://www.oecd.org/dac/financingsustainable-development/development-finance-standards/DACList-of-ODA-Recipients-for-reporting-2020-flows.pdf [Accessed 4 May 2021].

25 Husereau D, Drummond M, Petrou S, et al. Consolidated health economic evaluation reporting standards (cheers) statement. Eur $J$ Health Econ 2013;14:367-72.

26 Ogoina D. Fever, fever patterns and diseases called 'fever'--a review. J Infect Public Health 2011;4:108-24.

27 O'Connell ME, Boat T, Warner KE, eds. Preventing Mental, Emotional, and Behavioral Disorders Among Young People: Progress and Possibilities, 2009.

28 Jonas DE, Ferrari RM, Wines RC, et al. Evaluating evidence on intermediate outcomes: considerations for groups making healthcare recommendations. Am J Prev Med 2018:54:S38-52.

29 Aldridge RW, Iglesias D, Cáceres CF, et al. Determining a cost effective intervention response to HIV/AIDS in Peru. BMC Public Health 2009:9:352.

30 Fatti G, Jackson D, Goga AE, et al. The effectiveness and costeffectiveness of community-based support for adolescents receiving antiretroviral treatment: an operational research study in South Africa. J Int AIDS Soc 2018;21 Suppl 1.

31 Graves JC, Elyanu P, Schellack CJ, et al. Impact of a family clinic day intervention on paediatric and adolescent appointment adherence and retention in antiretroviral therapy: a cluster randomized controlled trial in Uganda. PLoS One 2018;13:e0192068.

32 MacKenzie RK, van Lettow M, Gondwe C, et al. Greater retention in care among adolescents on antiretroviral treatment accessing "Teen Club" an adolescent-centred differentiated care model compared with standard of care: a nested case-control study at a tertiary referral hospital in Malawi. J Int AIDS Soc 2017;20.

33 Colchero MA, Bautista-Arredondo S, Cortés-Ortiz MA, et al. Impact and economic evaluations of a combination prevention programme for men who have sex with men in Mexico. AIDS 2016;30:293-300.

34 Fung IC-H, Guinness L, Vickerman P, et al. Modelling the impact and cost-effectiveness of the HIV intervention programme amongst commercial sex workers in Ahmedabad, Gujarat, India. BMC Public Health 2007;7:195.

35 Gregson S, Adamson S, Papaya S, et al. Impact and process evaluation of integrated community and clinic-based HIV-1 control: a cluster-randomised trial in eastern Zimbabwe. PLoS Med 2007;4:e102.

36 Vassall A, Pickles M, Chandrashekar S, et al. Cost-Effectiveness of HIV prevention for high-risk groups at scale: an economic evaluation of the Avahan programme in South India. Lancet Glob Health 2014;2:e531-40.

37 Yun K, Chu Z, Zhang J, et al. Mobile phone intervention based on an HIV risk prediction tool for HIV prevention among men who have sex with men in China: randomized controlled trial. JMIR Mhealth Uhealth 2021;9:e19511.

38 Foster G, Orne-Gliemann J, Font $\mathrm{H}$, et al. Impact of facility-based mother support groups on retention in care and PMTCT outcomes in rural Zimbabwe: the EPAZ cluster-randomized controlled trial. J Acquir Immune Defic Syndr 2017;75 Suppl 2:S207-15. 
39 Sharma M, Farquhar C, Ying R, et al. Modeling the costeffectiveness of home-based HIV testing and education (hope) for pregnant women and their male partners in Nyanza Province, Kenya. J Acquir Immune Defic Syndr 2016;72 Suppl 2:S174-80.

40 Turan JM, Darbes LA, Musoke PL, et al. Development and Piloting of a home-based couples intervention during pregnancy and postpartum in southwestern Kenya. AIDS Patient Care STDS 2018;32:92-103.

41 Ndeffo Mbah ML, Kjetland EF, Atkins KE, et al. Cost-Effectiveness of a community-based intervention for reducing the transmission of Schistosoma haematobium and HIV in Africa. Proc Natl Acad Sci U S A 2013;110:7952-7.

42 Wang X, Guo G, Zheng J, et al. Programmes for the prevention of mother-to-child HIV infection transmission have made progress in Yunnan Province, China, from 2006 to 2015: a cost effective and cost-benefit evaluation. BMC Infect Dis 2019;19:64.

43 Ebenso BE, Tureta SM, Udo SO. Treatment outcome and impact of leprosy elimination campaign in Sokoto and Zamfara states, Nigeria. Lepr Rev 2001;72:192-8.

44 Khachadourian V, Truzyan N, Harutyunyan A, et al. Peoplecentred care versus clinic-based dot for continuation phase TB treatment in Armenia: a cluster randomized trial. BMC Pulm Med 2020;20:105.

45 Moualeu DP, Weiser M, Ehrig R. Optimal control for a tuberculosis model with undetected cases in Cameroon. Commun Nonlinear Sci Numer Simul 2015;20:986-1003.

46 Nagi MAM. Evaluation of a programme for control of Schistosoma haematobium infection in Yemen. East Mediterr Health $\mathrm{J}$ 2005;11:977-87.

47 Okeibunor JC, Orji BC, Brieger W, et al. Preventing malaria in pregnancy through community-directed interventions: evidence from Akwa Ibom state, Nigeria. Malar J 2011;10:227.

48 Suma TK, Shenoy RK, Kumaraswami V. Efficacy and sustainability of a footcare programme in preventing acute attacks of adenolymphangitis in Brugian filariasis. Trop Med Int Health 2002;7:763-6.

49 Chen Y-D, Li H-Z, Xu L-Q, et al. Effectiveness of a communitybased integrated strategy to control soil-transmitted helminthiasis and clonorchiasis in the people's Republic of China. Acta Trop 2021;214:105650.

50 Ahmed SA, Kumar A, Sethi P, et al. Effectiveness of education and antibiotic control programme at all India Institute of medical sciences, new Delhi. Nat/ Med J India 2018;31:262-7.

51 Apisarnthanarak A, Danchaivijitr S, Khawcharoenporn T, et al. Effectiveness of education and an antibiotic-control program in a tertiary care hospital in Thailand. Clin Infect Dis 2006;42:768-75.

52 Awad Al, Eltayeb IB, Baraka OZ. Changing antibiotics prescribing practices in health centers of Khartoum state, Sudan. Eur J Clin Pharmacol 2006;62:135-42.

53 Bantar C, Sartori B, Vesco E, et al. A hospitalwide intervention program to optimize the quality of antibiotic use: impact on prescribing practice, antibiotic consumption, cost savings, and bacterial resistance. Clin Infect Dis 2003;37:180-6.

54 Boyles TH, Naicker V, Rawoot N, et al. Sustained reduction in antibiotic consumption in a South African public sector Hospital; four year outcomes from the Groote Schuur Hospital antibiotic stewardship program. S Afr Med J 2017;107:115-8.

55 Butt SZ, Ahmad M, Saeed H, et al. Post-Surgical antibiotic prophylaxis: impact of pharmacist's educational intervention on appropriate use of antibiotics. J Infect Public Health 2019;12:854-60.

56 Hussain K, Khan MF, Ambreen G, et al. An antibiotic stewardship program in a surgical ICU of a resource-limited country: financial impact with improved clinical outcomes. J Pharm Policy Pract 2020;13:69.

57 Lester R, Haigh K, Wood A, et al. Sustained reduction in thirdgeneration cephalosporin usage in adult inpatients following introduction of an antimicrobial stewardship program in a large, urban hospital in Malawi. Clin Infect Dis 2020;71:e478-86.

58 Lu C, Liu Q, Yuan H, et al. Implementation of the smart use of antibiotics program to reduce unnecessary antibiotic use in a neonatal ICU: a prospective interrupted time-series study in a developing country. Crit Care Med 2019;47:E1-7.

59 Magedanz L, Silliprandi EM, dos Santos RP. Impact of the pharmacist on a multidisciplinary team in an antimicrobial stewardship program: a quasi-experimental study. Int J Clin Pharm 2012;34:290-4

$60 \mathrm{Ng} \mathrm{CK}$, Wu TC, Chan WMJ, et al. Clinical and economic impact of an antibiotics stewardship programme in a regional hospital in Hong Kong. Qual Saf Health Care 2008;17:387-92.
61 Okumura LM, Riveros BS, Gomes-da-Silva MM, et al. A costeffectiveness analysis of two different antimicrobial stewardship programs. Braz J Infect Dis 2016;20:255-61.

62 Ozgun H, Ertugrul BM, Soyder A, et al. Peri-Operative antibiotic prophylaxis: adherence to guidelines and effects of educational intervention. Int J Surg 2010;8:159-63.

63 Shi Q, Ding F, Sang R, et al. Drug use evaluation of cefepime in the first affiliated hospital of Bengbu medical college: a retrospective and prospective analysis. BMC Infect Dis 2013;13:160.

64 Song P, Li W, Zhou Q. An outpatient antibacterial stewardship intervention during the journey to $\mathrm{JCl}$ accreditation. $B M C$ Pharmacol Toxicol 2014;15:8.

65 Wei X, Zhang Z, Hicks JP, et al. Long-Term outcomes of an educational intervention to reduce antibiotic prescribing for childhood upper respiratory tract infections in rural China: follow-up of a cluster-randomised controlled trial. PLoS Med 2019;16:e1002733.

66 Zhang Z-G, Chen F, Chen J-Z. Introducing an antibiotic stewardship program in a pediatric center in China. World J Pediatr 2018;14:274-9.

67 Shawki MA, AISetohy WM, Ali KA, et al. Antimicrobial stewardship solutions with a smart innovative tool. J Am Pharm Assoc 2021;61:581-8.

68 Arulappen AL, Danial M, Haron N, et al. The impact of antimicrobial stewardship program on Injudicious use of cefuroxime. Front Pharmacol 2020;11:565818.

69 Apisarnthanarak A, Yatrasert A, Mundy LM, et al. Impact of education and an antifungal stewardship program for candidiasis at a Thai tertiary care center. Infect Control Hosp Epidemiol 2010;31:722-7.

70 Ilievska-Poposka B, Zakoska M, Talevski S. Practical Approach to Lung Health - Experience from the Republic of Macedonia. Open Access Maced J Med Sci 2018;6:618-23.

71 Imani P, Jakech B, Kirunda I, et al. Effect of integrated infectious disease training and on-site support on the management of childhood illnesses in Uganda: a cluster randomized trial. BMC Pediatr 2015;15:103

72 Mangham-Jefferies L, Wiseman V, Achonduh OA, et al. Economic evaluation of a cluster randomized trial of interventions to improve health workers' practice in diagnosing and treating uncomplicated malaria in Cameroon. Value Health 2014;17:783-91.

73 Reyes-Morales H, Flores-Hernández S, Tomé-Sandoval P, et al. A multifaceted education intervention for improving family physicians case management. Fam Med 2009;41:277-84.

74 Adams EJ, Garcia PJ, Garnett GP, et al. The cost-effectiveness of syndromic management in pharmacies in Lima, Peru. Sex Transm Dis 2003;30:379-87.

75 Goodman CA, Mutemi WM, Baya EK, et al. The cost-effectiveness of improving malaria home management: shopkeeper training in rural Kenya. Health Policy Plan 2006;21:275-88.

76 Hansen KS, Clarke SE, Lal S, et al. Cost-Effectiveness analysis of introducing malaria diagnostic testing in drug shops: a clusterrandomised trial in Uganda. PLoS One 2017;12:e0189758.

77 Kangwana BP, Kedenge SV, Noor AM, et al. The impact of retailsector delivery of artemether-lumefantrine on malaria treatment of children under five in Kenya: a cluster randomized controlled trial. PLoS Med 2011;8:e1000437.

78 Puchalski Ritchie LM, van Lettow M, Makwakwa A, et al. Impact of a tuberculosis treatment adherence intervention versus usual care on treatment completion rates: results of a pragmatic cluster randomized controlled trial. Implement Sci 2020;15:107.

79 Hansen KS, Ndyomugyenyi R, Magnussen P, et al. CostEffectiveness analysis of malaria rapid diagnostic tests for appropriate treatment of malaria at the community level in Uganda. Health Policy Plan 2017;32:676-89.

80 Zhang Z, Dawkins B, Hicks JP, et al. Cost-Effectiveness analysis of a multi-dimensional intervention to reduce inappropriate antibiotic prescribing for children with upper respiratory tract infections in China. Trop Med Int Health 2018;23:1092-100.

81 Losina E, Touré H, Uhler LM, et al. Cost-Effectiveness of preventing loss to follow-up in HIV treatment programs: a Côte d'Ivoire appraisal. PLoS Med 2009;6:e1000173.

82 Stella-Talisuna A, Bilcke J, Colebunders R, et al. Cost-Effectiveness of socioeconomic support as part of HIV care for the poor in an urban community-based antiretroviral program in Uganda. J Acquir Immune Defic Syndr 2014;67:e76-83.

83 Olney JJ, Eaton JW, Braitstein P, et al. Optimal timing of HIV homebased counselling and testing rounds in Western Kenya. J Int AIDS Soc 2018;21:e25142

84 Bautista-Arredondo S, La Hera-Fuentes G, Contreras-Loya D, et al. Efficiency of HIV services in Nigeria: determinants of unit cost 
variation of HIV counseling and testing and prevention of mother-tochild transmission interventions. PLoS One 2018;13:e0201706.

85 Yu Q, Zhao G-M, Hong X-L, et al. Impact and cost-effectiveness of a comprehensive schistosomiasis japonica control program in the Poyang lake region of China. Int J Environ Res Public Health 2013;10:6409-21.

86 Wiens MO, Kumbakumba E, Larson CP, et al. Scheduled follow-up referrals and simple prevention kits including counseling to improve post-discharge outcomes among children in Uganda: a proof-ofconcept study. Glob Health Sci Pract 2016;4:422-34.

87 Colchero MA, Contreras-Loya D, Lopez-Gatell H, et al. The costs of inadequate breastfeeding of infants in Mexico. Am J Clin Nutr 2015;101:579-86.

88 Wilson JW, Ramos JG, Castillo F, et al. Tuberculosis patient and family education through videography in El Salvador. J Clin Tuberc Other Mycobact Dis 2016;4:14-20.

89 Williamson PR, Altman DG, Blazeby JM, et al. Developing core outcome sets for clinical trials: issues to consider. Trials 2012;13:132.

90 Clarke M, Williamson PR. Core outcome sets and systematic reviews. Syst Rev 2016;5:11.

91 Gargon E, Gurung B, Medley N, et al. Choosing important health outcomes for comparative effectiveness research: a systematic review. PLoS One 2014;9:e99111.

92 Gargon E, Gorst SL, Harman NL, et al. Choosing important health outcomes for comparative effectiveness research: 4th annual update to a systematic review of core outcome sets for research. PLoS One 2018:13:e0209869.

93 Rosala-Hallas A, Bhangu A, Blazeby J, et al. Global health trials methodological research agenda: results from a priority setting exercise. Trials 2018;19:48.
94 Arnesen T, Nord E. The value of DALY life: problems with ethics and validity of disability adjusted life years. BMJ 1999;319:1423-5.

95 Luz A, Santatiwongchai B, Pattanaphesaj J. Identifying priority methodological issues in economic evaluation in low- and middle-income countries: finding the Holy Grail. F1000 Research 2017;6.

96 Barlam TF, Cosgrove SE, Abbo LM, et al. Implementing an antibiotic stewardship program: guidelines by the infectious diseases Society of America and the Society for healthcare epidemiology of America. Clin Infect Dis 2016:62:e51-77.

97 WHO Collaborating Centre for Drug Statistics Methodology. Guidelines for ATC classification and DDD assignment 2021, 2021. Available: https://www.whocc.no/filearchive/publications/2021 guidelines_web.pdf [Accessed 18 Mar 2021].

98 Cassini A, Högberg LD, Plachouras D, et al. Attributable deaths and disability-adjusted life-years caused by infections with antibioticresistant bacteria in the EU and the European economic area in 2015: a population-level modelling analysis. Lancet Infect Dis 2019;19:56-66.

99 Shrestha P, Cooper BS, Coast J, et al. Enumerating the economic cost of antimicrobial resistance per antibiotic consumed to inform the evaluation of interventions affecting their use. Antimicrob Resist Infect Control 2018;7:98.

100 Michaelidis Cl, Fine MJ, Lin CJ, et al. The hidden societal cost of antibiotic resistance per antibiotic prescribed in the United States: an exploratory analysis. BMC Infect Dis 2016;16:655.

101 Roope LSJ, Smith RD, Pouwels KB, et al. The challenge of antimicrobial resistance: what economics can contribute. Science 2019;364:eaau4679. 